Article

\title{
Evaluation of the Level of Sustainable Development of Provinces in China from 2012 to 2018: A Study Based on the Improved Entropy Coefficient-TOPSIS Method
}

\author{
Yuqing Liao ${ }^{1,+}$, Yongchao Ma ${ }^{2, *,+}$, Jingliang Chen ${ }^{1,+}$ and Ruirui Liu ${ }^{3,+}$ \\ 1 Business School, University of Shanghai for Science and Technology, Shanghai 200093, China; \\ liaoyuqing@usst.edu.cn (Y.L.); jingliangc@usst.edu.cn (J.C.) \\ 2 College of Engineering, North Dakota State University, Fargo, ND 58108-6050, USA \\ 3 School of Policing Studies, Shanghai University of Political Science and Law, Shanghai 201701, China; \\ liuruirui@shupl.edu.cn \\ * Correspondence: yongchao.ma@hotmail.com; Tel.: +1-701-231-8011 \\ + All the authors contributed equally to this paper.
}

Received: 20 February 2020; Accepted: 26 March 2020; Published: 30 March 2020

check for updates

\begin{abstract}
Based on the definition and implication of sustainable development, this paper first constructed an evaluation indicator system for the sustainable development level of provinces in China, and performed a scientific evaluation on the sustainable development level based on official statistics from 2012 to 2018 by using the improved Entropy Coefficient-TOPSIS (Technique for Order Preference by Similarity to an Ideal Solution) method. The evaluation results showed that the eastern region of China has the highest level of sustainable development, with its two municipalities directly under the central government, Beijing and Shanghai, achieving the full score of 1.0000 in all evaluations, both ranking first among all the provinces. There were significant differences in the level of sustainable development across provinces in the central region, which were comparatively weaker in terms of environmental sustainability and science and technology sustainability, with four provinces' evaluation scores below 0.5000 . The provinces of the western region had comparatively lower levels of sustainable development, with six of the provinces ranking among the bottom ten in the overall sustainability score. In the northeast region, Liaoning had the highest overall sustainable development level, ranking ninth in the country, with an evaluation score of 0.7726 ; however, there were large differences across the region, with the other two provinces ranking 19th and 21th, respectively, in the overall sustainability score. Based on the research findings, this paper has provided relevant policy recommendations for China to further improve the sustainable development level of various provinces in the future.
\end{abstract}

Keywords: sustainable development level; indicator system; Entropy Coefficient; TOPSIS method

\section{Introduction}

Since China has experienced nearly forty years of rapid economic growth, how to maintain sustainable development has become an issue of common concern to the academia [1-3]. In a broad sense, the sustainable development of a country is not only limited to the economic field, but also encompasses technological progress, reduced resource consumption, environmental improvement, and improvement in the quality of labor force, which essentially means that the entire society can "meet the needs of the present without compromising the ability of future generations to meet their own needs" [4]. 
However, the economic growth of China has followed an extensive development model with high energy consumption and heavy pollution [5-9]. The local governments are often too focused on quantitative growth but sacrifice the ecological environment to a large extent [10-13]. Therefore, the basic requirements of sustainable development are violated in the following aspects [14-16]:

(1) People's needs. China's traditional development model has overemphasized economic growth. This traditional development model refers to the fact that China's economic growth is mainly achieved by the large-scale input and expansion of production factors, while the quality, structure, efficiency, and technological level of production factors are basically unchanged. The essence base of this model is the growth rate of quantity, which relatively ignores the requirements of other aspects of sustainable development. In fact, this development model has weakened China's natural resource base to a certain extent and caused serious damage to the environment $[17,18]$. The local officials often excessively pursue the maximization of growth rate figures, while ignoring the limitation in resources and the damage caused to the ecological environment when pursuing economic growth [19-21]. This development model not only puts tremendous pressure on China's resources and environment, but also severely constrains the people's needs for a better life now and in the future, which contradicts the ultimate goal of sustainable development to meet people's needs [22,23];

(2) Fairness. One of the main themes of sustainable development is to achieve fairness not only among contemporary people, but also across generations, which is one fundamental difference between the traditional development model of China and the concept of sustainable development [24]. Under the traditional development model, very few considerations have been given to the interest of future generations and their need for resources and the environment during production and economic growth. Such a development model lacks responsibility for the intergenerational fairness in terms of resources and the environment;

(3) Harmony. Sustainable development is not only in an economic sense, but also covers sustainability in terms of resources, ecology, and the society as a whole. The past economic growth of China was supported by its resources, environment, and society, but made limited contribution to the resources, environment, and society. Therefore, the harmony of sustainable development is in question $[25,26]$;

(4) Sustainability. Sustainability means that one country can overcome various obstacles in its development process and maintain its ability to continuously develop and progress $[27,28]$. During China's development in recent years, resources and the environment have become important bottlenecks that constrain sustainability. Different types of environmental pollution, such as water pollution, air pollution, and solid waste pollution, have not only resulted in huge economic losses, but also seriously threaten the health and life of the people [29-31]. If these pollution issues are not treated and solved in a timely manner, sustainability will be impossible to achieve.

The academic community has conducted in-depth research on the topic of sustainable development in China. On the one hand, scholars have discussed the goals and significance of China's sustainable development. For example, Feng et al. compared the sustainable development of China with India, Vietnam, and Indonesia. They evaluated the development trends of those four countries from 1990 to 2015. Then, the key sustainable development goals of those four countries were identified and correlated by social network analysis models and principal component analysis method. They also analyzed the future directions for collaboration and concrete routes for sustainable development and proposed a collaborative development agenda for China and neighboring countries [32]. Liu et al. studied the relationship between sustainable development and social policies in China, in order to explore the interaction between welfare and development in China. After analyzing the new sustainability approach for Chinese social policy, they disclosed that this new approach highlights the significant meaning of China's policies for sustainable development and integrates the financial 
affordability and the adequacy of benefit levels into sustainable development. They also argued that social policy has become a key pillar of sustainable development besides economic and ecological objectives in China [33]. Wang et al. researched the social and economic factors behind the urban sprawl and their effects on sustainable development in China. They found that urban decentralization and urban renewal are the main factors promoting urban sprawl, which is characterized by de-densification and expansion of urbanized areas. By a dynamic analysis of the social, political, and cultural driving forces for urban sprawl with Beijing, Shanghai, and Guangzhou as examples, they indicated that the proper patterns of urban sprawl and strategies for urban expansion would help China to realize sustainable development [34]. Zhang et al. studied one of China's new sustainable development policies in 2015. This policy, named "Five Modernizations", includes industrialization, informatization, urbanization, agricultural modernization, and greenization. They analyzed the level, the trends, the patterns, and the determinants of each modernization by the panel data of 283 prefecture-level cities in China. Their results showed that the level of modernization and sustainable development in China experienced rapid growth during 2006-2015, especially in the Yangtze River Delta and Pearl River Delta region. They also argued that the results provide good example of the pathways and patterns of the sustainable development for other developing countries [35].

On the other hand, scholars have explored specific areas of sustainable development in China from perspectives like energy, industry, and environment. For example, Zhang and Lis focused on the production and use of biofuels to discuss China's sustainable development strategy, especially in the energy sector. They constructed the economic and mathematical model of bioethanol production to calculate the production capacity of fuel ethanol in China and evaluate the efficiency of bioethanol production. Their results disclosed the features of the biofuels used, and the economic processes with introducing biofuels into the ecological and economic systems of China. By discussing the consequences of transition to the production and use of biofuels, they finally analyzed the possible social, resource, and macroeconomic risks of such transition for sustainable development in China [36]. Zeng et al. studied the coal cities in China for energy security and sustainable development. By establishing the sustainability indicator system for coal cities in China, they used the decision tree model with the data mining method to analyze the sustainability of those cities. Their results showed that the resource curse pattern occurred in most mature coal cities in China, while resource curse and blessing patterns were presented in those declining coal cities. Moreover, coal cities in northeastern China had relatively better stainability than other ones. Although rapid economic growth has been achieved in northwestern coal cities, environment protection has also been ignored in those cities. Finally, they suggested that China's traditional conception of development should be replaced by effective plans for sustainable development [37]. Yuan et al. combined technological innovation with environment regulatory enforcement to study the sustainable development of China's industry. By panel data of 30 provinces in China from 2006 to 2015 with the sys-GMM (system-Generalized Method of Moments) method, they found that China's technological innovation can be significantly promoted by flexible environmental policies, which will have positive influences on industrial sustainable development. Moreover, although environmental regulation can positively moderate the environmental policies and technological innovation to facilitate industrial sustainable development in the eastern China, this influence is limited in the western regions [38].

However, there have been very few studies that comprehensively evaluate and analyze the sustainable development level of different provinces in China in recent years. Therefore, based on the definition and implication of sustainable development, this paper first constructs an evaluation indicator system for the sustainable development level of different provinces in China, and performs a scientific evaluation on the sustainable development level based on official statistics from 2012 to 2018 by using the improved Entropy Coefficient-Technique for Order Preference by Similarity to an Ideal Solution (TOPSIS) Method. Based on that, this paper derives relevant policy recommendations for achieving sustainable development in China in the future. This paper attempts to make academic contributions in the following two aspects: 
1. Systematically evaluate the sustainable development level and achievements of different provinces in China in recent years, not only enriching the academic literature on sustainable development evaluation, but also providing a reference to countries around the world, especially the developing countries, in assessing the sustainable development processes and formulating future sustainable development policies;

2. Further enrich the quantitative calculation methods for the sustainable development level by using an improved model, and provide a scientific basis for evaluating the sustainable development level of a region and a country.

The structure of this paper is arranged as follows: Section 2 constructs an evaluation indicator system for the sustainable development level of different provinces in China, introduces the data source of this paper and the improved entropy coefficient-TOPSIS method. Section 3 calculates the evaluation score of different provinces' sustainable development level from 2012 to 2018 based on the data and model introduced. Section 4 discusses the evaluation results, and Section 5 concludes the paper with policy recommendations on China's future sustainable development for reference by other countries, especially the developing countries.

\section{Materials and Methods}

\subsection{The Indicator System}

According to the theory of sustainable development and the limitations of China's traditional development model, the meaning of "sustainable development" in this paper included: (1) the foundation of sustainable development is to meet the requirements of resources and environment, and the development needs of future generations; (2) the premise of sustainable development is to continuously improve the quality and structure of production factors, and improve the efficiency and technical level of factor use; (3) the core of sustainable development is the improvement of development quality, with appropriately allocating and utilizing the factor inputs to achieve high-speed economic growth, rapid technological progress, continuous improvement of people's lives, and harmonious social development [39-41].

Therefore, this paper constructed an evaluation indicator system for the sustainable development level of different provinces in China from two dimensions: input and output. In constructing this indicator system, we fully considered the United Nations sustainable development indicator system [42,43] and the relevant research from the academic community [44-47], and carried out screening in accordance with the actual situation in China.

\subsubsection{Input Indicators}

(1) Human resource indicator. The development of the economy and society cannot happen without the input of human resources. The number of employed people is an important indicator of human resources. Therefore, this paper selected the number of employees in the primary industry, secondary industry, and tertiary industry in each province as the input indicator of human resources. The data of those indicators came from the National Bureau of Statistics of China [48]. In addition, the annual floating population of each province was chosen as another indicator of human resources to measure the fluctuation of the labor force input in China. The data of this indicator came from the China Migrants Dynamic Survey conducted by the National Health Commission in China [49].

(2) Material resource indicator. During the development of each province, water resources must be used for production and living, and energy is the material basis of human activities. The consumption of energy sources can generate other forms of energy, such as light, heat, and power, which can be utilized in production and people's daily lives. It is an important indicator of the sustainable development level of different provinces. Because the current energy structure of China is still dominated by coal [50,51], the total annual coal consumption and water resource consumption of each province were selected as the input indicators for material resources. The data of those indicators came from the National Bureau 
of Statistics of China [48]. Moreover, the Industrial Producer Price Index and the Fixed Asset Investment Price Index were selected to measure the price of material resources. The Industrial Producer Price Index is a relative number that reflects the trend and range of changes in the total ex-factory price level of all industrial products within a certain period of time. The ex-factory price of industrial products consists of three parts: production cost, profit, and taxes. It is the initial price of industrial products entering the circulation field, and it is also the basis for commercial enterprises and material departments to set wholesale prices, retail prices, and material supply prices. The ex-factory price index of industrial products can reflect the effect of changes in ex-factory prices on the total industrial output value. The Fixed Asset Investment Price Index is a relative number that reflects the price change trend and range of fixed asset investment in a certain period of time. The fixed asset investment amount consists of three parts: the completed investment in construction and installation projects, the completed investment in the purchase of equipment and tools, and the completed investment in other expenses. This index can accurately reflect the price change trends and ranges of various commodities and fee collection items involved in fixed asset investment, eliminate the price change factors in fixed asset investment indicators calculated at current prices, and truly reflect the scale and speed of fixed asset investment structure and benefits. These two indicators were calculated based on the raw data of the National Bureau of Statistics of China [48].

(3) Financial resource indicator. The financial resources of various provinces mainly include two parts: government expenditure and fixed asset investment. Government expenditure mainly consists of four parts: education expenditure, science and technology expenditure, medical and health expenditure, and environmental expenditure [48]. The amount of fixed asset investment is the total monetary amount of construction and purchase of fixed assets in a period of time, which can reflect the scale, growth speed, proportional structure, and direction of fund usage of fixed asset investment. Therefore, this paper selected the amount of fixed asset investment and the four government expenditure components as the input indicators for financial resources. The data of those indicators came from the National Bureau of Statistics of China [48].

\subsubsection{Output Indicators}

(1) Economic indicators. GDP (Gross Domestic Product) is an important indicator for the level of sustainable development of a local economy. In order to further decompose the economy, based on the current industrial structure of China, this paper selected the three indicators of annual value added of the primary industry, the secondary industry, and the tertiary industry as the output indicators for economic sustainability of each province. The data of those indicators came from the National Bureau of Statistics of China [48]. The Resident Consumption Level and Resident Consumption Index were also selected to reflect the economic status of residents in each province. The Resident Consumption Level refers to the extent to which residents have met their needs for survival, development, and enjoyment in the consumption of physical products and services. Its calculation method is the total consumption divided by the total population. The Resident Consumption Index reflects the degree of change in the consumption level of residents. The calculation method is the consumption level of the residents during the survey period $\times$ the consumption level index of the base period (usually 100$) \div$ the consumption level of the residents in the base period. These two indicators were calculated based on the raw data of the National Bureau of Statistics of China [48].

(2) Environmental indicators. Environmental sustainability is a crucial component of sustainable development for each province. It is not advisable to pursue economic growth but ignore environmental conservation, which violates the intention of sustainable development $[52,53]$. Based on the existing research of the academic community [44-47] and the recent severe air pollution and water pollution in China $[54,55]$, we selected carbon dioxide emission, sulfur dioxide emission, nitrogen oxides emission, and fume and dust emission to characterize the atmospheric environmental sustainability, and selected waste water discharge to reflect the water environmental sustainability of each province. Moreover, the volume of garbage innocuous disposal was also selected to reflect the sustainability 
of environmental protection in each province. The data of those indicators came from the National Bureau of Statistics of China [48] and the data center of the Ministry of Ecology and Environment of China [56].

(3) Science and technology indicators. The development in science and technology is an important measurement of the sustainable development level of each province. The advancement in science and technology can accelerate the transition of the development model towards a specialized, smart, and green development model, and eventually facilitates sustainable development [57]. Therefore, this paper selected the volume of transactions in the technology market and the number of patent applications by industrial enterprises above designated size as the output indicators for science and technology sustainability. The data of those indicators came from the National Bureau of Statistics of China [48].

(4) Social indicators. Social sustainability is reflected through the improvement in people's health and quality of life, covering numerous factors, such as life happiness, medical care, and education level [58,59]. Given China's actual situation and data availability, this paper selected the number of medical and health personnel, the number of college students, and per capita disposable income of each province as the output indicators for social sustainability. The data of those indicators came from the National Bureau of Statistics of China [48].

Therefore, this paper constructed an evaluation indicator system for sustainable development level, as shown in Table 1 below:

Table 1. Evaluation indicator system for the sustainable development level of provinces in China.

\begin{tabular}{|c|c|c|c|}
\hline Dimension & Category & Indicator & Unit \\
\hline \multirow{13}{*}{ Input Indicator } & \multirow{4}{*}{$\begin{array}{l}\text { Human resource } \\
\text { indicator }\end{array}$} & Number of employees in the primary industry & 10 Thousand People \\
\hline & & Number of employees in the secondary industry & 10 Thousand People \\
\hline & & Number of employees in the tertiary industry & 10 Thousand People \\
\hline & & Number of floating population & 10 Thousand People \\
\hline & \multirow{4}{*}{$\begin{array}{l}\text { Material resource } \\
\text { indicator }\end{array}$} & Coal consumption & 10 Thousand Tons \\
\hline & & Water resource consumption & 100 Million $\mathrm{m}^{3}$ \\
\hline & & Industrial producer price index & / \\
\hline & & Fixed asset investment price index & / \\
\hline & \multirow{5}{*}{$\begin{array}{l}\text { Financial resource } \\
\text { indicator }\end{array}$} & Education expenditure & 100 Million Yuan \\
\hline & & Science and technology expenditure & 100 Million Yuan \\
\hline & & Medical and health expenditure & 100 Million Yuan \\
\hline & & Environmental expenditure & 100 Million Yuan \\
\hline & & Fixed asset investment & 100 Million Yuan \\
\hline \multirow{15}{*}{ Output Indicator } & & Value added of the primary industry & 100 Million Yuan \\
\hline & & Value added of the secondary industry & 100 Million Yuan \\
\hline & Economic indicator & Value added of the tertiary industry & 100 Million Yuan \\
\hline & & Resident consumption level & Yuan per Person \\
\hline & & Resident consumption index & / 1 \\
\hline & \multirow{6}{*}{$\begin{array}{l}\text { Environmental } \\
\text { indicator }\end{array}$} & Waste water discharge & 10 Thousand Tons \\
\hline & & Volume of garbage innocuous disposal & 10 Thousand Tons \\
\hline & & Carbon dioxide emission & Tons \\
\hline & & Sulfur dioxide emission & Tons \\
\hline & & Nitrogen oxides emission & Tons \\
\hline & & Fume and dust emission & Tons \\
\hline & $\begin{array}{l}\text { Science and technology } \\
\text { indicator }\end{array}$ & Volume of transactions in the technology market & 100 Million Yuan \\
\hline & \multirow{3}{*}{ Social indicator } & & \\
\hline & & $\begin{array}{l}\text { Number of medical and health personnel } \\
\text { Number of college students }\end{array}$ & $\begin{array}{l}10 \text { Thousand People } \\
10 \text { Thousand People }\end{array}$ \\
\hline & & Disposable income per capita & Yuan \\
\hline
\end{tabular}

\subsection{Data and Research Period}

According to common practice in the academic circle, the provinces in this study did not include Hong Kong, Macao, Taiwan and Tibet region. The data sources of the above indicators were the National Bureau of Statistics of China [48], the China Migrants Dynamic Survey conducted by the 
National Health Commission in China [49], and the data center of the Ministry of Ecology and Environment of China [56]. The research period was from 2012 to 2018.

The reason for choosing this period is that despite the increasingly severe challenges facing China's resources and environment since the reform and opening-up, the central government did not pay attention to sustainable development and take practical actions early enough. In preparation for the United Nations (UN) Conference on Sustainable Development in Rio de Janeiro, Brazil in June 2012, China established the preparatory committee for UN Conference on Sustainable Development, jointly formed by 29 departments of the central government in April 2011, whose core units were from the National Development and Reform Commission (NDRC), the Ministry of Foreign Affairs, the Ministry of Science and Technology, the Ministry of Finance, and the Ministry of Environmental Protection. On 1 June 2012, China's first national report on sustainable development was officially published-The People's Republic of China National Report on Sustainable Development [60]. The research and maintenance work on sustainable development has since been carried out at the national level.

Therefore, this paper chose 2012-2018 (the official statistics of 2019 have not been fully released) as the research period in order to evaluate and analyze the sustainable development level of different provinces in the background of top-down national efforts in promoting sustainable development.

\subsection{Evaluation Methods}

\subsubsection{The Improved Entropy Coefficient Method}

Starting from the indicator system, this paper calculated the weight of economic sustainability, environmental sustainability, science and technology sustainability, and social sustainability in the overall sustainable development strength of different provinces by using the improved entropy coefficient method, and further obtained a set of public weights for the comprehensive evaluation of each province's level of sustainable development. The calculation steps are as follows:

(1) Determine the optimal element in each column. The optimal element is the one with the best value in evaluation indicators. Since all the evaluation indicators established above were positive indicators, the element with the largest indicator value was selected as the optimal element;

(2) Calculate the degree of approximation. The degree of approximation is the ratio of each element in the matrix to the optimal element of that column. After the degrees of approximation are calculated, they are used to form the Approximation Matrix $D_{i j}$ :

$$
D_{i j}=\frac{r_{i j}}{r_{j}^{*}}
$$

where $r_{i j}$ is the value of elements in column $j$ and $r_{j}^{*}$ is the value of the optimal element in that column;

(3) Normalize the approximation matrix $D_{i j}$ :

$$
d_{i j}=\frac{D_{i j}}{\sum_{i=1}^{n} \sum_{j=1}^{m} D_{i j}},
$$

in which the denominator $\sum_{i=1}^{n} \sum_{j=1}^{m} D_{i j}$ is the sum of all degrees of approximation in the approximation matrix $D_{i j}$;

(4) Calculate the entropy value. Calculate the entropy value $E_{j}$ of each indicator according to the normalized value:

$$
E_{j}=-\sum_{i=1}^{n} a_{i} \frac{d_{i j}}{d_{j}} \ln \frac{d_{i j}}{d_{j}}
$$

where $d_{j}=\sum_{i=1}^{n} d_{i j} . \quad a_{i}$ is the number of times each evaluation object appears in the evaluation. Since this paper evaluated each evaluation object once, $a_{i}$ was 1 . The entropy value $E_{j}$ is the weight of the $j^{\text {th }}$ evaluation indicator. 
For the approximation matrix $D_{i j}$ with both positive and negative elements, this paper adopted an improved normalization method so that the data were suitable for the calculation of entropy coefficients, thus improving the existing entropy coefficient method.

\subsubsection{The Improved TOPSIS Method}

The TOPSIS method is a multi-objective optimization method, which sorts the evaluation objects according to their degree of approximation with the optimal value in order to perform relative evaluation on the evaluation objects [61-63]. This paper intended to evaluate the sustainable development level of the 30 provinces in China by using the improved TOPSIS method, which improves the existing method by considering the characteristics of the indicator data for sustainability and adopting data processing methods that not only keep the nature of the original data, but also meet the requirements of the TOPSIS evaluation matrix.

There are two ideal solutions in the TOPSIS method: the positive solution (the optimal solution) and the negative solution (the worst solution). The optimal evaluation object should be closest to the optimal solution, while farthest from the worst solution. The evaluation result can be expressed by the degree of approximation $C$ whose range is $[0,1]$. The closer $C$ is to 1 , the better the evaluation result is, and vice versa [64-66].

The calculation steps are as follows:

(1) Construct the Characteristic Matrix B:

$$
B=\left[\begin{array}{ccccc}
x_{11} & \cdots & x_{1 j} & \cdots & x_{1 n} \\
x_{21} & \cdots & x_{2 j} & \cdots & x_{2 n} \\
\vdots & \vdots & \vdots & \vdots & \vdots \\
x_{m 1} & \cdots & x_{m j} & \cdots & x_{m n}
\end{array}\right](i=1,2,3 \cdots m ; j=1,2,3 \cdots n),
$$

where $x_{m j}$ is the value of the $j^{\text {th }}$ attribute of the $m^{\text {th }}$ object;

(2) Calculate the normalized vector. It is calculated by dividing each value by the module length of the column vector. $r_{i j}$ is the normalized attribute value:

$$
r_{i j}=\frac{x_{i j}}{\sqrt{\sum_{i=1}^{m} x_{i j}^{2}}} i=1,2, \ldots, m ; j=1,2, \ldots, n ;
$$

(3) Construct the weight normalization vector $v_{i j}$ :

$$
v_{i j}=E_{j} r_{i j} \quad i=1,2, \ldots, m ; j=1,2, \ldots, n,
$$

in which $E_{j}$ is the weight coefficient obtained by the improved entropy coefficient method introduced in Section 2.3.1;

(4) Determine the optimal solution $A^{*}$ and the worst solution $A^{-}$, where $A^{*}$ is the maximum value in the normalized matrix column, and $A^{-}$is the minimum value in the normalized matrix column:

$$
\begin{aligned}
& A^{*}=\left(\max _{i} v_{i j} \mid j \in J_{1}\right),\left(\min _{i} v_{i j} \mid j \in J_{2}\right), \mid i=1,2, \ldots, m=v_{1}^{*}, v_{2}^{*}, \ldots, v_{j}^{*}, \ldots, v_{n}^{*}, \\
& A^{-}=\left(\min _{i} v_{i j} \mid j \in J_{1}\right),\left(\max _{i} v_{i j} \mid j \in J_{2}\right), \mid i=1,2, \ldots, m=v_{1}^{-}, v_{2}^{-}, \ldots, v_{j}^{-}, \ldots, v_{n}^{-},
\end{aligned}
$$

(5) Calculate the object's distance $S^{*}$ from the optimal solution and the distance $S^{-}$from the worst solution:

$$
\begin{aligned}
& S^{*}=\sqrt{\sum_{j=1}^{n}\left(V_{i j}-v_{j}^{*}\right)^{2}}, \\
& S^{-}=\sqrt{\sum_{j=1}^{n}\left(V_{i j}-v_{j}^{-}\right)^{2}},
\end{aligned}
$$


(6) Calculate the degree of approximation $C_{i}^{*}$ :

$$
C_{i}^{*}=\frac{S_{i}^{-}}{\left(S_{i}^{*}+S_{i}^{-}\right)} \quad i=1,2, \cdots, m,
$$

where $0 \leq C_{i}^{*} \leq 1$. The greater the degree of approximation $C_{i}^{*}$, the better the evaluation result is; the smaller the degree of approximation $C_{i}^{*}$, the worse the evaluation result is;

(7) Determine the ranking of different provinces in terms of the sustainable development level according to the degree of approximation $C_{i}^{*}$.

Therefore, this paper ranked the sustainable development level of the provinces by using the improved entropy coefficient-TOPSIS method (the algorithm code for it can be found in Appendix A), thus not only keeping the characteristics of each evaluation indicator and incorporating all the information into evaluation decisions, but also facilitating comparison and derivation by making the data of the indicators dimensionless.

\section{Results}

Based on the data and methods in Section 2, this paper obtained the evaluation scores of the 30 provinces in China from 2012 to 2018 on economic sustainability, environmental sustainability, science and technology sustainability, and social sustainability, as well as the overall sustainable development level. The scores and rankings are shown in Table 2 below:

Table 2. The evaluation score and ranking of provinces in China from 2012 to 2018 in sustainable development.

\begin{tabular}{|c|c|c|c|c|c|c|}
\hline Rank & Province & $\begin{array}{c}\text { Overall } \\
\text { Sustainability }\end{array}$ & $\begin{array}{c}\text { Economic } \\
\text { Sustainability }\end{array}$ & $\begin{array}{l}\text { Environmental } \\
\text { Sustainability }\end{array}$ & $\begin{array}{c}\text { Science and } \\
\text { Technology } \\
\text { Sustainability }\end{array}$ & $\begin{array}{c}\text { Social } \\
\text { Sustainability }\end{array}$ \\
\hline 1 & Shanghai & 1.0000 & 1.0000 & 0.9984 & 0.9981 & 1.0000 \\
\hline 3 & Zhejiang & 0.9922 & 0.9861 & 1.0000 & 0.9975 & 0.9702 \\
\hline 4 & Guangdong & 0.9213 & 0.9757 & 0.9538 & 0.7907 & 0.9553 \\
\hline 6 & Tianjin & 0.8825 & 0.9297 & 0.8229 & 0.8697 & 0.9649 \\
\hline 7 & Shandong & 0.8663 & 0.9333 & 0.7949 & 1.0000 & 0.7607 \\
\hline 8 & Hainan & 0.7893 & 0.7456 & 0.9716 & 0.8813 & 0.3321 \\
\hline 9 & Liaoning & 0.7630 & 0.9570 & 0.8381 & 0.4029 & 0.8475 \\
\hline 10 & Fujian & 0.6974 & 0.8372 & 0.6243 & 0.5678 & 0.8559 \\
\hline 11 & Shaanxi & 0.6974 & 0.7925 & 0.6035 & 0.6054 & 0.9019 \\
\hline 15 & Chongqing & 0.6621 & 0.7437 & 0.4852 & 0.7188 & 0.8630 \\
\hline 16 & Ningxia & 0.6489 & 0.7109 & 0.8301 & 0.2376 & 0.7284 \\
\hline 17 & Shanxi & 0.6402 & 0.7514 & 0.6002 & 0.4101 & 0.8925 \\
\hline 18 & Henan & 0.6312 & 0.8385 & 0.5030 & 0.4235 & 0.9305 \\
\hline 19 & Heilongjiang & 0.6272 & 0.7504 & 0.4502 & 0.5745 & 0.9228 \\
\hline 20 & Jilin & 0.6186 & 0.8280 & 0.4157 & 0.5653 & 0.8712 \\
\hline 21 & Hunan & 0.5982 & 0.7198 & 0.4805 & 0.4750 & 0.8627 \\
\hline 22 & Inner Mongolia & 0.5894 & 0.8428 & 0.4802 & 0.4004 & 0.7719 \\
\hline 23 & Hebei & 0.5756 & 0.7976 & 0.4233 & 0.3898 & 0.8802 \\
\hline 24 & Guangxi & 0.5642 & 0.7261 & 0.4679 & 0.3543 & 0.8516 \\
\hline 25 & Guizhou & 0.5574 & 0.6377 & 0.4995 & 0.3837 & 0.8093 \\
\hline
\end{tabular}


Figures 1 and 2 depict the evaluation results of the provinces in terms of their overall sustainable development level and their economic sustainability, environmental sustainability, science and technology sustainability, and social sustainability, respectively.

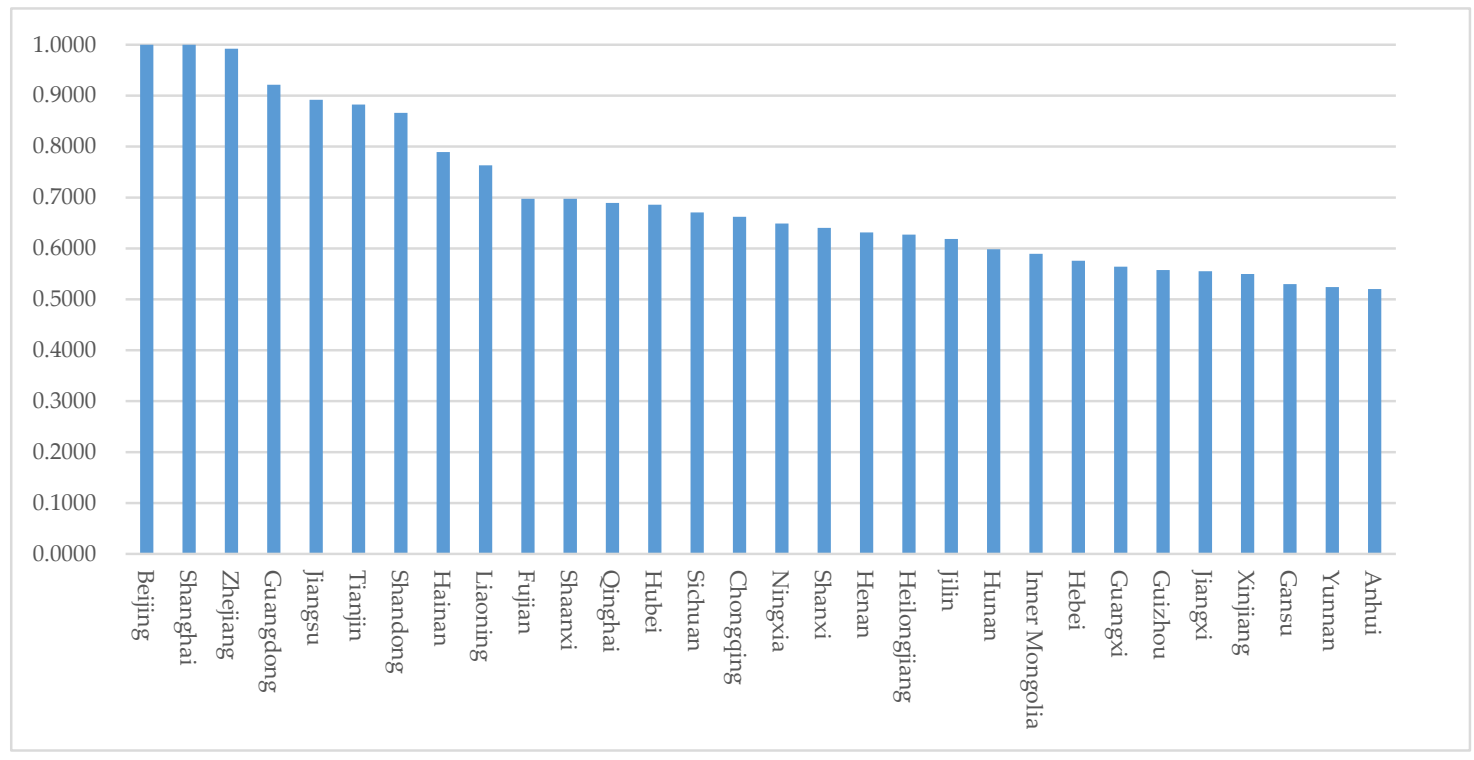

Figure 1. The evaluation score of the overall sustainable development level of provinces in China from 2012 to 2018.

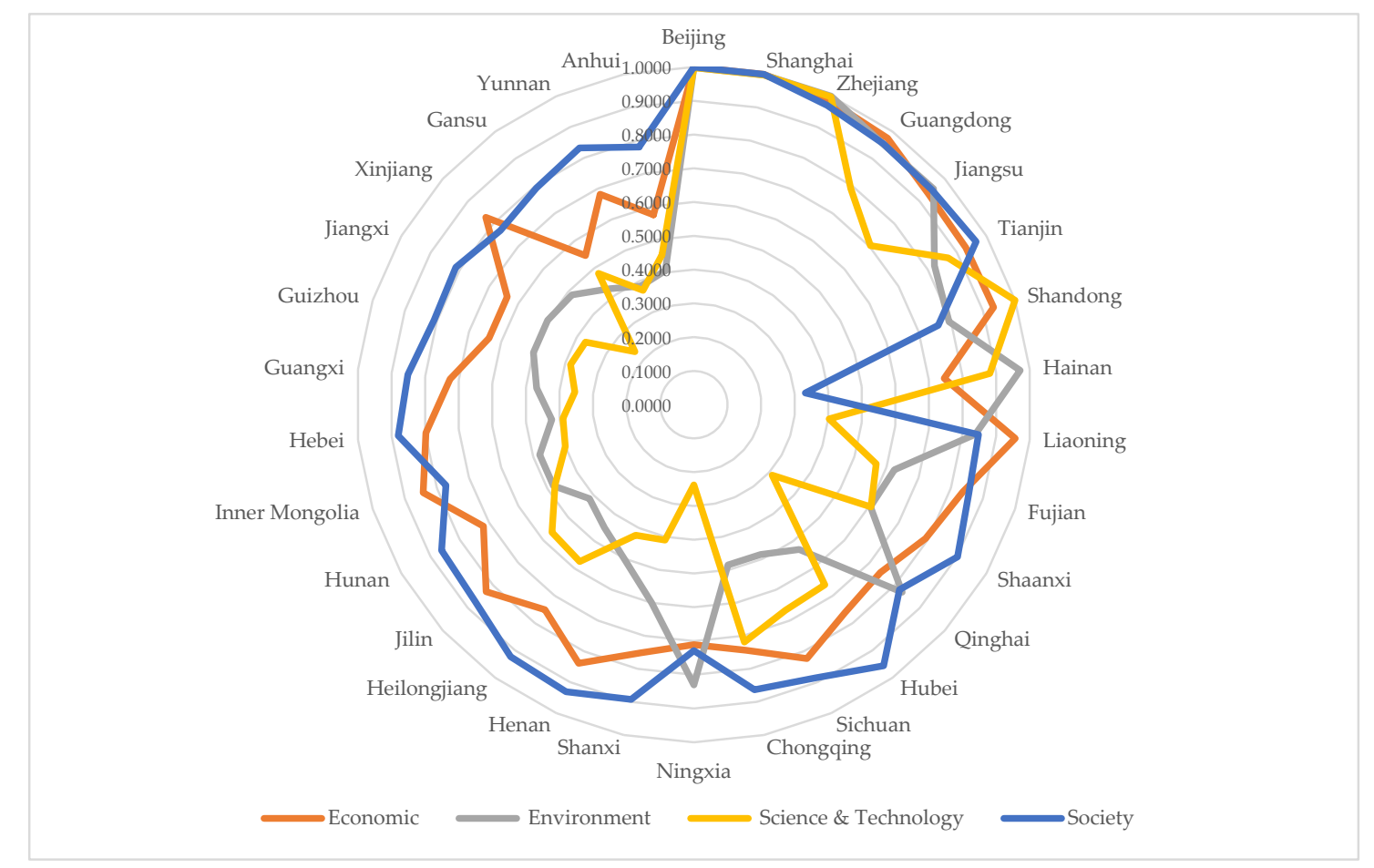

Figure 2. The evaluation scores of the economic, environmental, science and technology, and social sustainability of provinces in China from 2012 to 2018.

\section{Discussion}

Based on above calculation results, this paper found the following characteristics in the sustainable development level of provinces in China from 2012 to 2018. 


\subsection{Overall Characteristics}

From 2012 to 2018, the evaluation scores of the 30 provinces in China on the overall sustainable development level were all above 0.5000 , of which the scores of 9 provinces were above 0.7000 , and those of 4 provinces were above 0.9000 , indicating that the provinces in China generally performed quite well in sustainable development, and that more than $10 \%$ of the provinces showed excellent levels of sustainable development.

However, in terms of different areas of sustainable development, the scores in environmental sustainability and science and technology sustainability were not optimistic. In the science and technology sustainability area, there were 15 provinces with an evaluation score of under 0.5000 , while in the environmental sustainability area, there were 14 provinces with an evaluation score of under 0.5000 . There were eight provinces with an evaluation score of under 0.4000 in terms of science and technology sustainability, and those of Xinjiang and Ningxia were even lower than 0.3000 , with that of Xinjiang being the lowest, at 0.2349 . In terms of environmental sustainability, the evaluation score of Yunnan was less than 0.4000 .

On the other hand, there was significant polarization in the sustainable development level of provinces in China. The capital Beijing and the economic center Shanghai both achieved a full score of 1.000 in the overall sustainable development level, as well as the economic and social areas of sustainability, followed by Zhejiang (overall sustainability score 0.9922), Guangdong (overall sustainability score 0.9213 ), and Jiangsu (overall sustainability score 0.8917 ). All of these are the most economically and socially developed regions of China. In contrast, among the less developed provinces, Yunnan had an overall sustainability score of 0.5240 , an environmental sustainability score of 0.3847 , and a science and technology sustainability score of 0.3706; Xinjiang had an overall sustainability score of 0.5497 and a science and technology sustainability score of 0.2349 . There are large differences in the evaluation scores.

This paper would like to further discuss the sustainable development level of provinces by region based on the official geographical classification by the National Bureau of Statistics of China [67].

\subsection{The Eastern Region}

The eastern region covers Beijing, Tianjin, Hebei, Shanghai, Jiangsu, Zhejiang, Fujian, Shandong, Guangdong, and Hainan. This region had the highest overall level of sustainable development in China, with 9 provinces ranking top 10 in the overall sustainability score (the only exception is Hebei). In particular, Beijing and Shanghai both ranked first in the country. Tianjin, as one of the four municipalities directly under the central government, ranked sixth in the country, with an overall sustainability score of 0.8825 . However, it is worth noticing that its evaluation score in environmental sustainability was the lowest among all evaluation scores (0.8229), indicating that although the Beijing-Tianjin-Hebei region has made progress in air pollution control in recent years, it still needs to put emphasis on environmental sustainability $[68,69]$. In the eastern region, due to its geographical location and small population, Hainan is relatively weak in social sustainability (evaluation score 0.3321). Hainan has relatively smaller numbers of medical and health personnel and college students $[70,71]$, which calls for further improvement in the future.

\subsection{The Central Region}

The central region covers six provinces: Shanxi, Anhui, Jiangxi, Henan, Hubei, and Hunan. The evaluation results show that there are significant differences in the level of sustainable development across the region. The overall sustainability scores of Hubei, Shanxi, Henan, and Hunan were relatively high, while those of Anhui and Jiangxi were relatively low (ranking the lowest and fifth lowest, respectively). It is more worth noticing that although provinces in this region showed strong economic sustainability (with the lowest score of Anhui being 0.5201), these provinces are weak in terms of 
environmental sustainability and science and technology sustainability. The evaluation scores of Hunan, Anhui, and Jiangxi in these two areas of sustainability were below 0.5000 .

The main reason for this is that since the reform and opening up, China has not paid sufficient attention to the sustainable development of the central region, resulting in poor sustainability of provinces in the central region amid the national strategies of "opening up the East" and "developing the West" [72]. Until 2010, after the State Council issued the "Plan on Promoting the Rise of the Central Region" [73], the provinces in this region have seen gradual improvement in their sustainable development level [74]. However, when compared with the coastal provinces in the eastern region, the six central provinces are still relatively weak in the sustainable development level. These provinces have been focused on economic growth, while neglecting the cultivation and maintenance of strength in environmental sustainability and science and technology sustainability $[75,76]$, resulting in lower sustainable development level of the central region.

\subsection{The Western Region}

The western region includes 12 provinces, including Inner Mongolia, Guangxi, Chongqing, Sichuan, Guizhou, Yunnan, Shaanxi, Gansu, Qinghai, Ningxia, Xinjiang, and Tibet. Since Tibet was not included in the research scope, as mentioned above, this paper will focus on the remaining 11 provinces.

It can be seen that the 11 western provinces' level of sustainable development was the lowest compared with other regions, with 6 of the provinces ranking among the bottom 10 in the overall sustainability score. Yunnan even had the lowest evaluation score in environmental sustainability in the country. Except for Sichuan and Shaanxi, these provinces' level of sustainable development was at the lower middle level. The main reason is that these provinces are located in the underdeveloped western region, with a low level of urbanization and sustainable development $[77,78]$. In the process of China's reform and opening up, the western region located far inland does not have much contact or exchange with the rest of the provinces or foreign countries $[79,80]$. In addition, the eastern coastal region with rapid economic growth has been given a lot of support and preferential policies, while it was not until 2000 that the Fifth Plenary Session of the 15th CPC Central Committee passed the "Suggestions of the Central Committee of the CPC on Formulating the Tenth Five-year Plan for National Economic and Social Development", which emphasized the implementation of the "developing the West" strategy and speeding up the development of the Midwest region [81].

Therefore, from 2012 to 2018, although the economic sustainability level of the western provinces was still at a lower level compared with the rest of the country, the evaluation scores were all above 0.5000 (with the lowest score of 0.5240 from Yunnan), proving a certain strength in economic sustainability. However, the environmental sustainability and science and technology sustainability of the western provinces were still quite low and need further improvement in the future [82].

\subsection{The Northeast Region}

The Northeast region includes the three provinces of Liaoning, Jilin, and Heilongjiang, among which Liaoning had the highest overall sustainable development level (ranking ninth in the country with a score of 0.7630 ), while Heilongiiang and Jilin ranked relatively behind. However, the environmental sustainability and science and technology sustainability of these provinces were not outstanding, with Liaoning's science and technology sustainability score of only 0.4029 , and Heilongjiang's and Jilin's environmental sustainability scores being only 0.4502 and 0.4157 , respectively.

The Northeast region is a traditional industrial base of China. However, during the reform and opening up, a large number of state-owned enterprises have closed down and large numbers of employees have become unemployed, resulting in a serious lag in development. Not only is its economic development gradually lagging behind the eastern coastal region, its level of sustainable development is also facing major challenges [83]. Regarding this, China has set up a plan to revitalize the old industrial base in the Northeast [84], but the imbalance in development still exists among the three provinces. Because Liaoning is closer to the eastern provinces and faces the sea, it has a strong 
geographical advantage and has gradually concentrated the population, funding, and technology in the Northeast region [85], thus enjoying a higher level of economic, environmental, science and technology, and social sustainability. On the other hand, Jilin and Heilongjiang are lagging behind on all areas of sustainability, with lower-ranking evaluation scores of overall sustainable development level (ranking 19th and 20th, respectively).

\subsection{Interregional Comparison}

Interregional comparison of the above four regions revealed:

1. The overall sustainability of eastern provinces is in the leading position in China. This region includes Beijing-Tianjin-Hebei, the Yangtze River Delta (excluding cities in Anhui), and the Pearl River Delta, which are the most economically developed regions in China. Its economic sustainability also represents the best level of China. However, in the field of environmental sustainability, the evaluation scores of Tianjin, Shandong, and Fujian were lower than those of Liaoning, Ningxia, and Qinghai, and the evaluation score of Hebei was the fourth lowest in the country (0.4233). The above results show that the air pollution and water pollution in the eastern provinces, especially the Beijing-Tianjin-Hebei region, have restricted their sustainable development, especially in terms of environmental sustainability;

2. Although the central and western provinces lag behind the eastern region in terms of overall and economic sustainability, they still have many bright spots in the areas of environmental, scientific and technological, and social sustainability. For example, Qinghai and Ningxia were ranked eighth and ninth in environmental sustainability; Chongqing and Sichuan were ranked eighth and tenth in science and technology sustainability; Hubei, Henan, and Shaanxi were ranked fifth, eighth, and tenth in social sustainability, respectively. The above results show that although the evaluation scores of the central and western provinces during 2012-2018 were not as good as those of the eastern provinces, they still have strong development potential;

3. Although the sustainability of provinces in the Northeast region in recent years is not very optimistic, Liaoning has certain advantages nationwide in the areas of economic and environmental sustainability. Moreover, Heilongjiang and Jilin also have some advantages in the areas of scientific and technological and social sustainability. Therefore, the three provincial governments should consider giving full play to their own advantages to promote the sustainability of the entire region in the future.

\section{Conclusions}

Based on the definition and implication of sustainable development, this paper first constructed an evaluation indicator system for the sustainable development level of provinces in China, and performed a scientific evaluation on the sustainable development level based on official statistics from 2012 to 2018 by using the improved Entropy Coefficient-TOPSIS Method. The evaluation results showed that the eastern region of China had the highest level of sustainable development, with its two municipalities directly under the central government, Beijing and Shanghai, achieving the full score of 1.0000 in all evaluations, both ranking first among all the provinces. There were significant differences in the level of sustainable development across provinces in the central region, which were comparatively weaker in terms of environmental sustainability and science and technology sustainability, with four provinces' evaluation scores below 0.5000 . The provinces of the western region had comparatively lower levels of sustainable development, with six of the provinces ranking among the bottom ten in the overall sustainability score. In the northeast region, Liaoning had the highest overall sustainable development level, ranking ninth in the country with an evaluation score of 0.7726 ; however, there were large differences across the region, with the other two provinces ranking 19th and 21st, respectively, in the overall sustainability score.

There were still two limitations in this paper, which need to be further improved in our future research:

(1) Although this paper selected indicators from input and output dimensions to build the comprehensive evaluation indicator system for the sustainable development level, it was still difficult 
to fully cover all areas and directions required for sustainable development. We will draw on the latest research results of the academic community to further improve this indicator system;

(2) As this paper focused on the evaluation and analysis of the sustainable development of provinces in China, international comparisons need to be further strengthened in future research to adopt the advanced experience of developed countries in the field of sustainable development.

Based on the research findings, this paper has summarized the following policy recommendations for China to further improve the sustainable development level of various provinces in the future.

(1) Formulate sustainable development strategies covering all areas of sustainability, including economic, environmental, science and technology, and social sustainability according to the actual conditions and characteristics of different provinces. Given the different levels of sustainable development in different regions of China, it is necessary to make tailored and targeted strategic plans to maintain and enhance sustainable development in accordance with the actual conditions and characteristics of each province. For the eastern provinces with the highest level of sustainable development, they need to further enhance the weak areas (such as the science and technology sustainability of Jiangsu, evaluation score 0.7085 ; and the environmental sustainability of Shandong, evaluation score 0.7879 ) while maintaining the currently high sustainability level. For the central and northeastern provinces, they should work hard to close the gap between provinces and improve the sustainability level of weaker provinces, such as Jiangxi, Anhui, Heilongjiang, and Jilin, while improving the overall sustainable development level. For the western provinces with the lowest sustainable development level, they need to formulate a detailed and comprehensive sustainable development plan and gradually improve their sustainability level in all areas.

(2) Facilitate the development of science and technology, adjust the industrial structure, and improve the weak areas of provinces with low levels of environmental and science and technology sustainability. According to the evaluation results, there are a number of provinces with weak environmental and science and technology sustainability. The root cause is their flawed industrial structure-low-level traditional industries with high resource and energy consumption and heavy pollution have taken a large proportion in economically dominant industries, leading to a low economic sustainability and weakening their environmental and science and technology sustainability. Therefore, these provinces need to facilitate the development of high and new technology as well as achieve a high-tech transformation of the industrial structure under the leadership of the central government in order to improve their weak areas in environmental and science and technology sustainability.

Author Contributions: Conceptualization, Y.L.; Methodology, Y.M.; Software, J.C.; Validation, R.L.; Formal Analysis, Y.L.; Investigation, Y.M.; Resources, J.C.; Data Curation, Y.M.; Writing-original draft preparation, Y.L. and R.L.; Writing-review and editing, J.C. and R.L.; Visualization, J.C. and R.L.; Supervision, Y.L.; Project Administration, Y.M. All authors have read and agreed to the published version of the manuscript.

Funding: This research received no external funding.

Conflicts of Interest: The authors declare no conflict of interest. 


\section{Appendix A. Algorithm Code for the Improved TOPSIS Method}

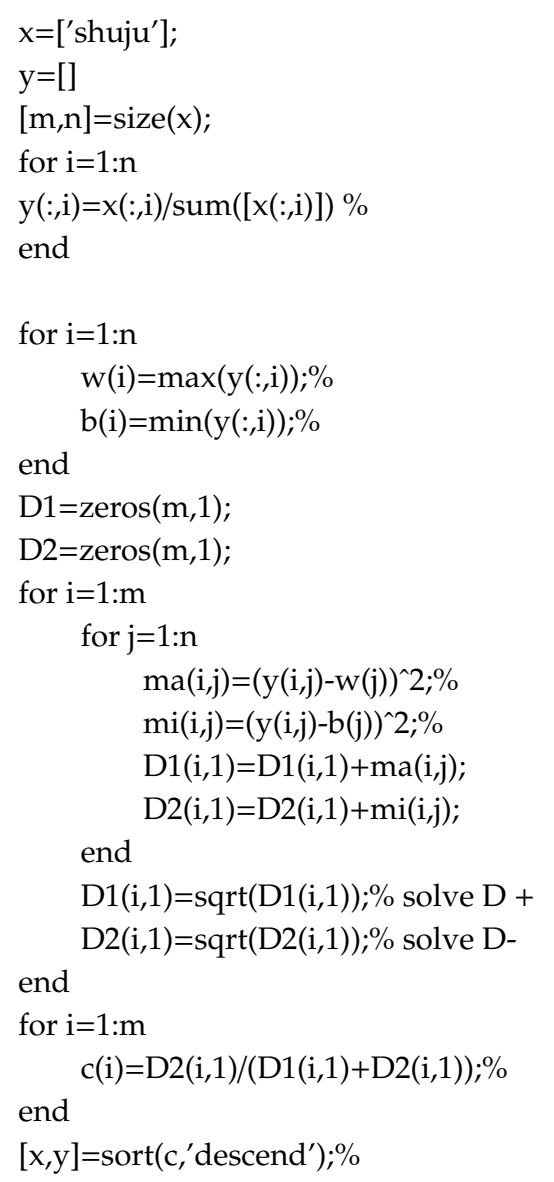

\section{References}

1. Yuan, G.; Yang, W. Study on optimization of economic dispatching of electric power system based on Hybrid Intelligent Algorithms (PSO and AFSA). Energy 2019, 183, 926-935. [CrossRef]

2. Yang, W.X.; Li, L.G. Analysis of Total Factor Efficiency of Water Resource and Energy in China: A Study Based on DEA-SBM Model. Sustainability 2017, 9, 1316. [CrossRef]

3. Kattel, G.R.; Shang, W.; Wang, Z.; Langford, J. China's South-to-North Water Diversion Project Empowers Sustainable Water Resources System in the North. Sustainability 2019, 11, 3735. [CrossRef]

4. World Commission on Environment and Development. Our Common Future; Oxford University Press: Oxford, UK, 1987.

5. Li, K.; Fang, L.; He, L. How population and energy price affect China's environmental pollution? Energy Policy 2019, 129, 386-396. [CrossRef]

6. Yang, W.; Li, L. Energy Efficiency, Ownership Structure, and Sustainable Development: Evidence from China. Sustainability 2017, 9, 912. [CrossRef]

7. Miao, Z.; Baležentis, T.; Shao, S.; Chang, D. Energy use, industrial soot and vehicle exhaust pollution-China's regional air pollution recognition, performance decomposition and governance. Energy Econ. 2019, 83, 501-514. [CrossRef]

8. Zhu, Y.; Wang, Z.; Yang, J.; Zhu, L. Does renewable energy technological innovation control China's air pollution? A spatial analysis. J. Clean. Prod. 2020, 250, 119515. [CrossRef]

9. Yang, W.; Li, L. Efficiency evaluation of industrial waste gas control in China: A study based on data envelopment analysis (DEA) model. J. Clean. Prod. 2018, 179, 1-11. [CrossRef]

10. Zheng, S.; Kahn, M.E.; Sun, W.; Luo, D. Incentives for China's urban mayors to mitigate pollution externalities: The role of the central government and public environmentalism. Reg. Sci. Urban Econ. 2014, 47, 61-71. [CrossRef] 
11. Yang, W.; Li, L. Efficiency Evaluation and Policy Analysis of Industrial Wastewater Control in China. Energies 2017, 10, 1201. [CrossRef]

12. Wu, H.; Li, Y.; Hao, Y.; Ren, S.; Zhang, P. Environmental decentralization, local government competition, and regional green development: Evidence from China. Sci. Total Environ. 2020, 708, 135085. [CrossRef] [PubMed]

13. Hong, T.; Yu, N.; Mao, Z. Does environment centralization prevent local governments from racing to the bottom? -Evidence from China. J. Clean. Prod. 2019, 231, 649-659. [CrossRef]

14. Bastas, A.; Liyanage, K. Setting a framework for organisational sustainable development. Sustain. Prod. Consum. 2019, 20, 207-229. [CrossRef]

15. Corona, B.; Shen, L.; Reike, D.; Carreón, J.R.; Worrell, E. Towards sustainable development through the circular economy-A review and critical assessment on current circularity metrics. Resour. Conserv. Recycl. 2019, 151, 104498. [CrossRef]

16. Chowdhury, M.M.H.; Agarwal, R.; Quaddus, M. Dynamic capabilities for meeting stakeholders' sustainability requirements in supply chain. J. Clean. Prod. 2019, 215, 34-45. [CrossRef]

17. Li, J.; Shi, X.; Wu, H.; Liu, L. Trade-off between economic development and environmental governance in China: An analysis based on the effect of river chief system. China Econ. Rev. 2020, 60, 101403. [CrossRef]

18. Liu, L.; Di, B.; Zhang, M. The tradeoff between ecological protection and economic growth in China's county development: Evidence from the soil and water conservation projects during 2011-2015. Resour. Conserv. Recycl. 2020, 156, 104745. [CrossRef]

19. Lee, S.; Oh, D.W. Economic growth and the environment in China: Empirical evidence using prefecture level data. China Econ. Rev. 2015, 36, 73-85. [CrossRef]

20. Liu, J.; Qu, J.; Zhao, K. Is China's development conforms to the Environmental Kuznets Curve hypothesis and the pollution haven hypothesis? J. Clean. Prod. 2019, 234, 787-796. [CrossRef]

21. Liang, W.; Yang, M. Urbanization, economic growth and environmental pollution: Evidence from China. Sustain. Comput. Inform. Syst. 2019, 21, 1-9. [CrossRef]

22. Sebestyén, V.; Bulla, M.; Rédey, Á.; Abonyi, J. Data-driven multilayer complex networks of sustainable development goals. Data Br. 2019, 25, 104049. [CrossRef] [PubMed]

23. Howe, P. The triple nexus: A potential approach to supporting the achievement of the Sustainable Development Goals? World Dev. 2019, 124, 104629. [CrossRef]

24. Kwatra, S.; Kumar, A.; Sharma, P. A critical review of studies related to construction and computation of Sustainable Development Indices. Ecol. Indic. 2020, 112, 106061. [CrossRef]

25. Li, Y.; Yang, W.; Shen, X.; Yuan, G.; Wang, J. Water Environment Management and Performance Evaluation in Central China: A Research Based on Comprehensive Evaluation System. Water 2019, 11, 2472. [CrossRef]

26. Da Silva, J.; Fernandes, V.; Limont, M.; Rauen, W.B. Sustainable development assessment from a capitals perspective: Analytical structure and indicator selection criteria. J. Environ. Manag. 2020, 260, 110147. [CrossRef]

27. Williams, S.; Robinson, J. Measuring sustainability: An evaluation framework for sustainability transition experiments. Environ. Sci. Policy 2020, 103, 58-66. [CrossRef]

28. Yang, W.; Yuan, G.; Han, J. Is China's air pollution control policy effective? Evidence from Yangtze River Delta cities. J. Clean. Prod. 2019, 220, 110-133. [CrossRef]

29. Shen, X.; Yang, W.; Sun, S. Analysis of the Impact of China's Hierarchical Medical System and Online Appointment Diagnosis System on the Sustainable Development of Public Health: A Case Study of Shanghai. Sustainability 2019, 11, 6564. [CrossRef]

30. Khan, I.; Kabir, Z. Waste-to-energy generation technologies and the developing economies: A multi-criteria analysis for sustainability assessment. Renew. Energy 2020, 150, 320-333. [CrossRef]

31. Li, L.; Yang, W. Total Factor Efficiency Study on China's Industrial Coal Input and Wastewater Control with Dual Target Variables. Sustainability 2018, 10, 2121. [CrossRef]

32. Feng, T.; Kang, Q.; Pan, B.; Yang, Y. Synergies of sustainable development goals between China and countries along the Belt and Road initiative. Curr. Opin. Environ. Sustain. 2019, 39, 167-186. [CrossRef]

33. Liu, T.; Li, Y.; Tian, T. Reinterpreting the Connotation of "Sustainability" and the Expansion of Social Policy in China. Sustainability 2019, 11, 1814. [CrossRef]

34. Wang, X.; Shi, R.; Zhou, Y. Dynamics of urban sprawl and sustainable development in China. Socioecon. Plann. Sci. 2019, 100736. [CrossRef] 
35. Zhang, P.; Yuan, H.; Tian, X. Sustainable development in China: Trends, patterns, and determinants of the "Five Modernizations" in Chinese cities. J. Clean. Prod. 2019, 214, 685-695. [CrossRef]

36. Zhang, Z.; Lis, M. Modeling Green Energy Development Based on Sustainable Economic Growth in China. Sustainability 2020, 12, 1368. [CrossRef]

37. Zeng, L.; Guo, J.; Wang, B.; Lv, J.; Wang, Q. Analyzing sustainability of Chinese coal cities using a decision tree modeling approach. Resour. Policy 2019, 64, 101501. [CrossRef]

38. Yuan, B.; Zhang, Y. Flexible environmental policy, technological innovation and sustainable development of China's industry: The moderating effect of environment regulatory enforcement. J. Clean. Prod. 2020, 243, 118543. [CrossRef]

39. Chang, R.; Zuo, J.; Zhao, Z.; Zillante, G.; Gan, X.; Soebarto, V. Evolving theories of sustainability and firms: History, future directions and implications for renewable energy research. Renew. Sustain. Energy Rev. 2017, 72, 48-56. [CrossRef]

40. Yang, Y.; Yang, W. Does Whistleblowing Work for Air Pollution Control in China? A Study Based on Three-party Evolutionary Game Model under Incomplete Information. Sustainability 2019, 11, 324. [CrossRef]

41. Eustachio, J.H.P.P.; Caldana, A.C.F.; Liboni, L.B.; Martinelli, D.P. Systemic indicator of sustainable development: Proposal and application of a framework. J. Clean. Prod. 2019, 241, 118383. [CrossRef]

42. The Department of Economic and Social Affairs of the United Nations. Indicators of Sustainable Development: Guidelines and Methodologies. Available online: https:/www.un.org/esa/sustdev/natlinfo/indicators/ guidelines.pdf (accessed on 6 March 2020).

43. The Development Data and Outreach Branch of United Nations Statistics Division. Final List of Proposed Sustainable Development Goal Indicators. Available online: https://sustainabledevelopment.un.org/content/ documents/11803Official-List-of-Proposed-SDG-Indicators.pdf (accessed on 6 March 2020).

44. Bell, S.; Morse, S. Delivering sustainability therapy in sustainable development projects. J. Environ. Manag. 2005, 75, 37-51. [CrossRef] [PubMed]

45. Bell, S.; Morse, S. Problem structuring methods: Theorizing the benefits of deconstructing sustainable development projects. J. Oper. Res. Soc. 2007, 58, 576-587. [CrossRef]

46. Bell, S.; Morse, S. Experiences with sustainability indicators and stakeholder participation: A case study relating to a 'Blue Plan' project in Malta. Sustain. Dev. 2004, 12, 1-14. [CrossRef]

47. Bell, S.; Morse, S. Sustainability Indicators: Measuring the Immeasurable? 2nd ed.; Routledge: Abingdon, UK, 2008.

48. National Bureau of Statistics of China. China Statistical Yearbook, 2012-2018; China Statistic Press: Beijing, China, 2019.

49. Migrant Population Service Center of National Health Commission. China Migrants Dynamic Survey, 2012-2018. Available online: http://www.chinaldrk.org.cn/wjw/\#/home (accessed on 6 March 2020).

50. Li, Y.; Chiu, Y.; Lin, T. Coal production efficiency and land destruction in China's coal mining industry. Resour. Policy 2019, 63, 101449. [CrossRef]

51. Chen, X.; Liang, Q.; Liu, L.; Wang, C.; Xue, M. Critical structural adjustment for controlling China's coal demand. J. Clean. Prod. 2019, 235, 317-327. [CrossRef]

52. Liu, Z.; Ding, M.; He, C.; Li, J.; Wu, J. The impairment of environmental sustainability due to rapid urbanization in the dryland region of northern China. Landsc. Urban Plan. 2019, 187, 165-180. [CrossRef]

53. Sun, H.; Mohsin, M.; Alharthi, M.; Abbas, Q. Measuring environmental sustainability performance of South Asia. J. Clean. Prod. 2020, 251, 119519. [CrossRef]

54. Gao, H.; Yang, W.; Yang, Y.; Yuan, G. Analysis of the Air Quality and the Effect of Governance Policies in China's Pearl River Delta, 2015-2018. Atmosphere 2019, 10, 412. [CrossRef]

55. Yang, W.; Yang, Y. Research on Air Pollution Control in China: From the Perspective of Quadrilateral Evolutionary Games. Sustainability 2020, 12, 1756. [CrossRef]

56. Data Center of Ministry of Ecology and Environment of the People's Republic of China. Environmental Quality Data, 2012-2018. Available online: http://datacenter.mee.gov.cn/websjzx/queryIndex.vm (accessed on 6 March 2020).

57. Secundo, G.; Ndou, V.; Del Vecchio, P.; Pascale, G. De Sustainable development, intellectual capital and technology policies: A structured literature review and future research agenda. Technol. Forecast. Soc. Chang. 2020, 153, 119917. [CrossRef] 
58. Lee, K.; Jung, H. Dynamic semantic network analysis for identifying the concept and scope of social sustainability. J. Clean. Prod. 2019, 233, 1510-1524. [CrossRef]

59. Himanshu, H.; Arokiasamy, P.; Talukdar, B. Illustrative effects of social capital on health and quality of life among older adult in India: Results from WHO-SAGE India. Arch. Gerontol. Geriatr. 2019, 82, $15-21$. [CrossRef] [PubMed]

60. China Preparatory Committee for the United Nations Conference on Sustainable Development. The People's Republic of China National Report on Sustainable Development; People's Publishing House: Beijing, China, 2012.

61. Hwang, C.L.; Yoon, K. Methods for Multiple Attribute Decision Making. In Multiple Attribute Decision Making: Methods and Applications A State-of-the-Art Survey; Springer Berlin Heidelberg: Berlin, Germany, 1981; pp. 58-191, ISBN 978-3-642-48318-9.

62. De Farias Aires, R.F.; Ferreira, L. A new approach to avoid rank reversal cases in the TOPSIS method. Comput. Ind. Eng. 2019, 132, 84-97. [CrossRef]

63. Chen, P. Effects of normalization on the entropy-based TOPSIS method. Expert Syst. Appl. 2019, 136, 33-41. [CrossRef]

64. Kacprzak, D. A doubly extended TOPSIS method for group decision making based on ordered fuzzy numbers. Expert Syst. Appl. 2019, 116, 243-254. [CrossRef]

65. Palczewski, K.; Sałabun, W. The fuzzy TOPSIS applications in the last decade. Procedia Comput. Sci. 2019, 159, 2294-2303. [CrossRef]

66. Zhang, L.; Wang, T.; Li, H.; Huang, B.; Zhou, X. Agent evaluation based on multi-source heterogeneous information table using TOPSIS. Adv. Eng. Inform. 2019, 42, 100971. [CrossRef]

67. National Bureau of Statistics of China. The Division of Eastern, Western, Central and Northeast Region in China. Available online: http://www.stats.gov.cn/ztjc/zthd/sjtjr/dejtjkfr/tjkp/201106/t20110613_71947.htm (accessed on 30 January 2020).

68. Yuan, G.; Yang, W. Evaluating China's Air Pollution Control Policy with Extended AQI Indicator System: Example of the Beijing-Tianjin-Hebei Region. Sustainability 2019, 11, 939. [CrossRef]

69. Xiao, C.; Chang, M.; Guo, P.; Gu, M.; Li, Y. Analysis of air quality characteristics of Beijing-Tianjin-Hebei and its surrounding air pollution transport channel cities in China. J. Environ. Sci. 2020, 87, 213-227. [CrossRef]

70. Hainan Provincial Bureau of Statistics and Hainan Investigation Team of National Bureau of Statistics of China. Hainan Statistical Yearbook, 2012-2018; China Statistic Press: Beijing, China, 2019.

71. Dong, H.; Li, P.; Feng, Z.; Yang, Y.; You, Z.; Li, Q. Natural capital utilization on an international tourism island based on a three-dimensional ecological footprint model: A case study of Hainan Province, China. Ecol. Indic. 2019, 104, 479-488. [CrossRef]

72. The State Council Information Office of the People's Republic of China. Review and Prospect of China's Regional Policy and Regional Development. Available online: http://www.scio.gov.cn/ztk/xwfb/04/5/ Document/542304/542304.htm (accessed on 30 January 2020).

73. The State Council Information Office of the People's Republic of China. Plan on Promoting the Rise of the Central Region. Available online: http://www.scio.gov.cn/ztk/xwfb/04/4/Document/542282/542282.htm (accessed on 30 January 2020).

74. Tian, Y.; Wang, L. Mutualism of intra- and inter-prefecture level cities and its effects on regional socio-economic development: A case study of Hubei Province, Central China. Sustain. Cities Soc. 2019, 44, 16-26. [CrossRef]

75. Wang, Y.; Lu, Y.; He, G.; Wang, C.; Yuan, J.; Cao, X. Spatial variability of sustainable development goals in China: A provincial level evaluation. Environ. Dev. 2019, 100483. [CrossRef]

76. Tao, Y.; Li, F.; Crittenden, J.; Lu, Z.; Ou, W.; Song, Y. Measuring urban environmental sustainability performance in China: A multi-scale comparison among different cities, urban clusters, and geographic regions. Cities 2019, 94, 200-210. [CrossRef]

77. Yang, F.; Yang, M.; Xue, B.; Luo, Q. The effects of China's western development strategy implementation on local ecological economic performance. J. Clean. Prod. 2018, 202, 925-933. [CrossRef]

78. Jia, J.; Ma, G.; Qin, C.; Wang, L. Place-based Policies, State-Led Industrialisation, and Regional Development: Evidence from China's Great Western Development Programme. Eur. Econ. Rev. 2020, 123, 103398. [CrossRef]

79. Huang, H.; Wei, Y.D. Spatial inequality of foreign direct investment in China: Institutional change, agglomeration economies, and market access. Appl. Geogr. 2016, 69, 99-111. [CrossRef] 
80. Wei, Y.D.; Li, H.; Yue, W. Urban land expansion and regional inequality in transitional China. Landsc. Urban Plan. 2017, 163, 17-31. [CrossRef]

81. The Fifth Plenary Session of the 15th Central Committee of the Communist Party of China. Suggestions of the Central Committee of the CPC on Formulating the Tenth Five-year Plan for National Economic and Social Development. Available online: https://www.ndrc.gov.cn/fggz/fzzlgh/gjfzgh/200709/ P020191029595688741033.pdf (accessed on 30 January 2020).

82. Fan, Y.; Fang, C. Evolution process analysis of urban metabolic patterns and sustainability assessment in western China, a case study of Xining city. Ecol. Indic. 2020, 109, 105784. [CrossRef]

83. Wan, L.; Zhang, Y.; Qi, S.; Li, H.; Chen, X.; Zang, S. A study of regional sustainable development based on GIS/RS and SD model—Case of Hadaqi industrial corridor. J. Clean. Prod. 2017, 142, 654-662. [CrossRef]

84. CPC Central Committee and The State Council of China. Several Opinions on Comprehensively Revitalizing the Old Industrial Bases in the Northeast and Other Regions. Available online: http://www.gov.cn/zhengce/ 2016-04/26/content_5068242.htm (accessed on 30 January 2020).

85. Xie, H.; Wang, W.; Yang, Z.; Choi, Y. Measuring the sustainable performance of industrial land utilization in major industrial zones of China. Technol. Forecast. Soc. Chang. 2016, 112, 207-219. [CrossRef]

(C) 2020 by the authors. Licensee MDPI, Basel, Switzerland. This article is an open access article distributed under the terms and conditions of the Creative Commons Attribution (CC BY) license (http://creativecommons.org/licenses/by/4.0/). 